\title{
A Instabilidade do Processo Civil em Tempos de Pandemia e seus Efeitos em Contratos e Relações de Consumo
}

\author{
The Instability of Civil Process in Pandemic Times and its Effects on Contracts and Consumer \\ Relations
}

Gleiner Pedroso Ferreira Ambrosio'

'Universidade Presbiteriana Mackenzie, Brasil

\section{Resumo}

O presente artigo se propõe a analisar os presentes impactos à atividade processual brasileira em decorrência da pandemia da COVID-19, seja analisando os prejuízos à estabilidade dos órgãos julgadores, seja abordando o posicionamento jurisprudencial destes frente às novas demandas sociais, em especial às questões consumeristas.

Palavras-chave: processo civil; pandemia; instabilidade processual; relações consumeristas

\begin{abstract}
This article proposes to analyze the present impacts on the Brazilian procedural activity due to the COVID-19 pandemic, either by analyzing the damage to the stability of organs judging bodies, or by addressing their jurisprudential position in the face of new social demands, especially regarding consumer issues.

Keywords: civil procedure; pandemic; procedural instability; consumer relations
\end{abstract}

\section{Introdução}

A inesperada ascensão da pandemia da COVID-19 atingiu, de forma inquestionável, quase todos os setores da sociedade atual, direta ou indiretamente. E em um país com elevado grau de judicialização como o Brasil, diante de uma situação ainda mais atípica como a de uma pandemia, certamente tais impactos reverberaram no todo do Direito brasileiro (e mundial, claro), sendo a atividade processual civil (para além das outras esferas processuais, como penal, trabalhista e público-administrativa) uma das componentes dessa equação.

Então, compreendendo a existência desse cenário onde, além das demandas já pré-existentes em relação à pandemia, o surgimento de novas demandas (ou a intensificação das já existentes) fez com que a atuação jurisdicional dos tribunais passasse por desafios mais complexos. Assim sendo, serão expostos os diversos prejuízos ao sistema de estabilidades processuais (com especial enfoque para questões consumeristas) onde, através de análise jurisprudencial ${ }^{1}$, legal e doutrinária, procurar-se-á

1 Ressalta-se que, para fins de análise jurisprudencial e de dados relevantes à proposta, o presente artigo buscará a pormenorização de tribunais de diferentes regiões, uma vez que os impactos da COVID-19 foram bastante esparsos no território nacional (ainda que alguns tenham efeitos mais segmentados regionalmente) 
apontar sua atual incidência nos tribunais, o peso à coletividade e o posicionamento dos julgadores, sempre buscando apresentar quais os reais impactos e resultados.

\section{Prejuízo ao Sistema de Estabilidades Processuais}

O processo civil, por regra, tem como busca a estabilidade das demandas entre os litigantes, ponto em que se referenda, por exemplo, pelo instituto da preclusão (art. 507 do CPC), sujeita a ser aplicada nas partes do processo. Mais precisamente, antes mesmo de se adentrar em questões de prazo (bastante sensíveis, mas que terão desenvolvimento posterior), por meio da produção da petição inicial, apresentam-se os elementos da demanda que, no decorrer dos diversos momentos processuais, receberão as devidas apreciações que indicarão progressiva estabilização de tais elementos²

Nesse teor do processo, um dos principais estágios responsáveis por, efetivamente, trazer maior estabilidade diz respeito ao saneamento, pois implica na análise categorizada pelo juiz em relação às mínimas condições processuais da demanda, desde as providências preliminares até as possibilidades do art. 357 do CPC.

Por assim ser, dentre os diversos prejuízos ao sistema processual brasileiro decorrentes da epidemia da COVID-19, aqui se encontra uma de suas primeiras celeumas: sabendo que o findar da referida fase de saneamento do processo constitui limite para a alteração do pedido ou da causa de pedir (art. 329, II), caso vícios existentes não venham a ser devidamente constatados pelo juízo, assim se prosseguirá no andamento do processo (entendimento esse consubstanciado pelo enunciado 490, do $\mathrm{FPPC}^{3}$ ), configurando um problema inicial desde tais momentos processuais, que afetará as outras duas fases seguintes. E quais eventos culminaram em tal cenário?

As alterações que contribuíram para tal residem, para além de questões controversas e ainda discutidas por especialistas (realização de audiências, possíveis fraudes em oitivas ou audiências virtuais, dentre outras anteriores ou posteriores à apreciação do mérito) em um ponto em específico: o surgimento de novas problemáticas quanto à análise de mérito.

Antes de abordá-lo, deve-se enfatizar o seguinte ponto: no primeiro ano da pandemia da COVID-19, começaram a surgir certas preocupações em profissionais do direito quanto a um possível aumento no volume de ações a serem ingressadas na justiça durante e após a pandemia, o que certamente configuraria uma problemática a mais ao sistema de estabilidade processual:

Quando indagado por Gonet sobre a percepção do advogado em relação ao aumento ou redução do quantitativo
de ações e litígios ingressados na Justiça durante a pandemia, Vieira Souto compartilhou outra preocupação. "Eu
acho que ainda não houve um ingresso no Judiciário da massa de processos que certamente virá. O ministro Dias
Toffoli já externou, e outros ministros também, sobre a possibilidade de, depois da pandemia, termos uma crise
judicial", afirmou

Todavia, de acordo com dados recentes do relatório "Justiça em Números 2021" pelo $\mathrm{CNJ}$, ficou claro que tal realidade, até o momento, não se concretizou. Inclusive, as informações indicam que a tendência de diminuição dos processos tem perdurado desde o ano de 2017. Obviamente, o relatório faz referência até o final do ano de 2020, ainda em meio à pandemia. Ainda assim, a tendência

2 SOUZA, André Pagani de. CARACIOLA, Andrea Boari. ASSIS, Carlos Augusto de. FERNANDES, Luís Eduardo Simardi. DELLORE, Luiz. Teoria Geral do Processo Contemporâneo, 4ª edição. Grupo GEN, 2018, p. 251.

3 Tal enunciado trata de outras questões processuais relevantes, onde se pontua a referida: Enunciados do Fórum Permanente de Processualistas Civis. Florianópolis, 2017. Disponível em: https://institutodc.com.br/wp-content/ uploads /2017/06/FPPC-Carta-de-Florianopolis.pdf. Acesso em: 22/04/2021.

4 ESCOLA Superior do Ministério Público da União. Especialista analisa desafios enfrentados pelo direito processual civil e as perspectivas após a pandemia. Brasília, DF:2020. Disponível em: http:/ / escola.mpu.mp.br /a-escola / comunicacao / noticias / especialista-analisa-desafios-enfrentados-pelo-direito-processual-civil-e-as-perspectivas-futuras-apos-a-pandemia.

5 CONSELHO Nacional de Justiça. Justiça em Números 2021. Brasília, DF: 2021. Disponível em: https: / / www.cnj.jus. $\mathrm{br} / \mathrm{wp}$-content/uploads /2021/09/relatorio-justica-em-numeros2021-12.pdf 
é de que a série histórica de diminuição perdure ao menos a curto prazo, tal como exposto na seguinte tabela:

Figura 1 - Série histórica dos casos novos e processos baixados - indicação de queda

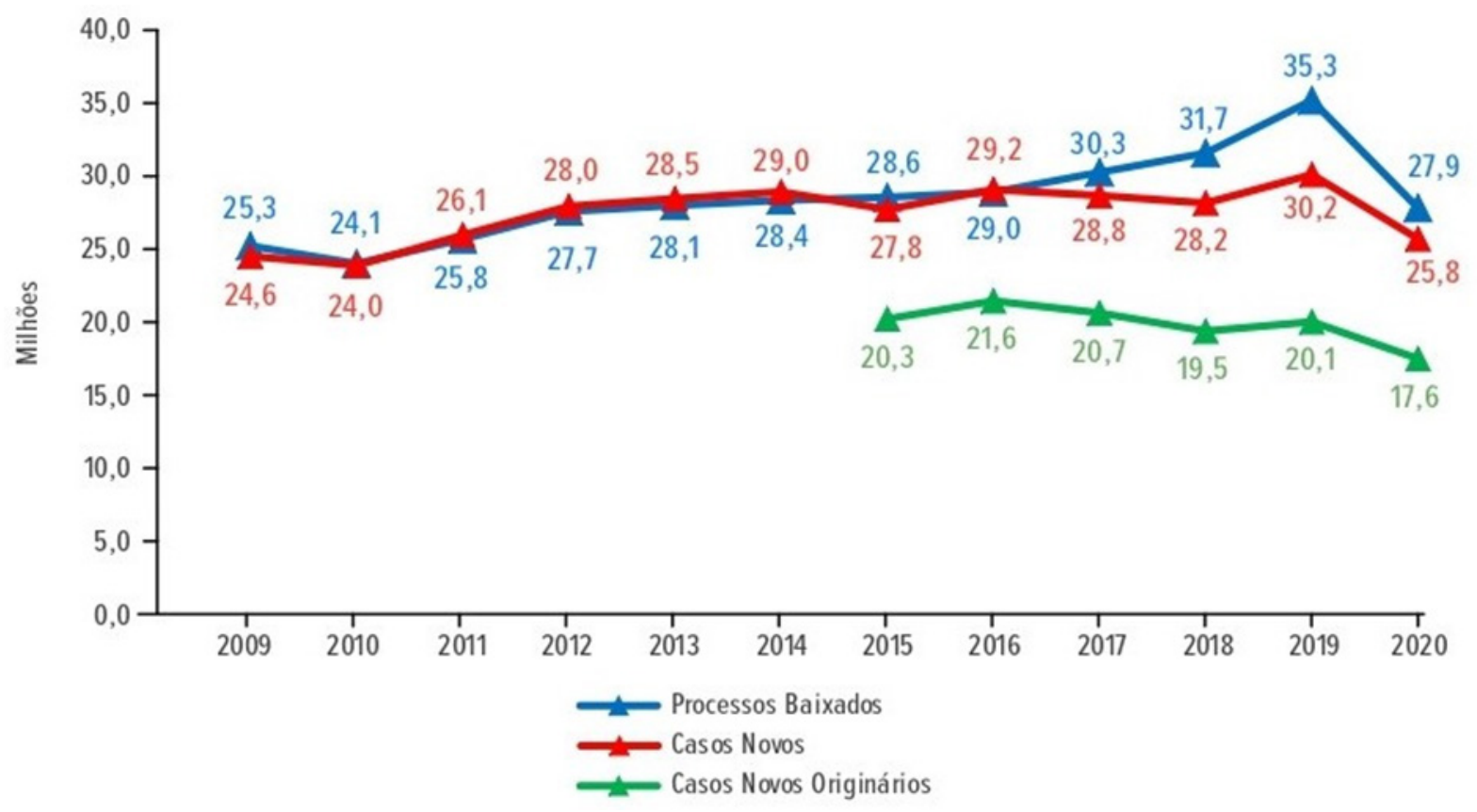

Fonte: Relatório Justiça em Números 2021 do CNJ

Obviamente, caso se opte por adotar uma perspectiva mais restritiva e segmentada referente a essa esfera "macro" processual, é possível apontar que determinados (e poucos) setores sofreram algum aumento em sua atividade processual, sendo alguns deles bastante sensíveis, a exemplo do âmbito trabalhista: no próprio relatório anterior do CNJ emitido em 31 de dezembro de 2020, foi indicado que o Tribunal Superior do Trabalho (TST), órgão notoriamente com elevado número de casos, julgou 318.053 processos em todo o ano de 2020. A marca é 6,3\% superior aos números registrados em 2019, quando o Tribunal encerrou o ano com 299.186 casos julgados ${ }^{6}$. Todavia, ressaltando, não passa de fenômeno localizado, sem se permitir inferir qualquer aumento generalizado no volume de processos, uma vez o próprio relatório mais recente ter indicado uma continuidade na clara tendência de queda no volume de processos.

Assim como dito, portanto, o ponto central analisado que se constituiu em um dos que mais atuou negativamente no sistema de estabilidades processuais na pandemia não residiu em critérios meramente numéricos, mas sim qualitativos: com o advento de toda a vasta problemática da COVID-19, uma pluralidade de áreas foi impactada severamente tanto pela gravidade do vírus quanto pela falta de preparo e incerteza quanto aos impactos provenientes ${ }^{7}$. Dessa forma, diversas relações de consumo e de prestação de serviço foram absolutamente impactadas tanto do ponto de vista do prestador/ vendedor quanto do consumidor, o que trouxe novos desafios não só no aspecto de organização do poder judiciário para analisar essas novas demandas (impacto nos prazos), mas também no preparo que os agentes julgadores precisaram adquirir para atender às urgentes demandas sociais. Tamanho foi

6 CONSELHO Nacional de Justiça. TST aumenta em 6,3\% a quantidade de processos julgados em 2020. Disponível em: https://www.cnj.jus.br/tst-aumenta-em-63-a-quantidade-de-processos-julgados-em-2020/. Último acesso em: $11 / 07 / 2021$.

7 Tal como detalhado no artigo "Pandemia e direito civil: instrumentos para efetivação da autonomia privada", destaca-se o seguinte trecho: "Desde o início da pandemia, alertava-se para a questão de que não haveria, no Brasil, uma infraestrutura capaz de suportar os efeitos da doença, caracterizada pela sua rápida disseminação, pelo alto índice de contágio e por provocar sérios problemas respiratórios para uma parcela dos contaminados. Por essa razão, a diretriz principal do Ministério da Saúde foi, a partir da declaração do estado de pandemia pela OMS, que as pessoas ficassem em suas casas e evitassem contatos diretos e próximos com outros”. BACCARIN, Cínthia. CORDIOLI, Hiago Andrioti. CANAVEZ, Luciana Lopes. Revista de Direitos Fundamentais nas Relações do Trabalho, Sociais e Empresariais. v. 6, n. 2, p. 01 - 21, Jul/Dez. 2020. 
o impacto que a emergência da pandemia da COVID-19 se constituiu, em vários casos, como elemento de ensejo à relativização de prestação de serviços, de renegociação de dívidas, enfim, pontos que serão oportuna e brevemente analisados no item seguinte.

Fica incontroverso que, portanto, com a conjugação de tais elementos, decerto a capacidade de análise e organização na apreciação das demandas encontrar-se-ão sobrecarregadas, onde não necessariamente o juiz deixará de apreciar eventuais vícios ao processo em suas primeiras fases, mas certamente, ressaltando, contribuirá para a sobrecarga de análise em um estágio essencial para o andamento deste.

\section{Obrigação de Fazer e Reflexos da Referida Instabilidade}

Como exposto anteriormente, um dos pontos certamente mais atingidos no presente limiar diz respeito às obrigações de fazer em relações de consumo ${ }^{8}$ (sejam aquelas contraídas antes ou durante a pandemia). Tal como conhecido na matéria de Direito do Consumidor, a própria parte do consumidor representa aquela que deve receber maior proteção na relação entre as partes, o que se referenda por vários expostos do CDC (Código de Defesa do Consumidor), a exemplo de seu art. $4^{\circ}$, I ${ }^{9}$. Mas isso, claro, não quer dizer que a parte hipossuficiente terá a razão na análise de mérito ou, ainda mais, que não poderá ser responsabilizada frente a alguma culpa ou dolo ${ }^{10}$

Por pressuposto, tal como ocorre em relações processuais trabalhistas, a parte mais vulnerável da relação parte de maior "vantagem" no caso concreto, uma vez possuir maior amparo legal no ordenamento jurídico nacional. Todavia, como reflexo dos diferentes impactos da pandemia, o prejuízo à atividade dos órgãos processuais e seus respectivos julgadores acabou por implicar em uma falta de uniformidade nos julgamentos e nas jurisprudências de casos sensíveis à presente época, o que, por si só, configura uma falta de segurança jurídica aos consumidores submetidos ao processo. Para fins de comprovação dessa tese, serão expostos alguns trechos de jurisprudências que tratem de pontos, como anteriormente dito, sensíveis e próximos aos impactos da pandemia, mas que, por diferentes situações, culminaram em posicionamentos fortemente opostos.

Para começar, ao ser analisado o seguinte agravo de instrumento ${ }^{11}$ proferido na $2^{a}$ Câmara Direito Privado do Tribunal de Justiça do Estado do Ceará ${ }^{12}$, uma concessionária de energia havia cessado o fornecimento de seu serviço sob justificativa de que, com a ascensão da pandemia da COVID-19, não haveria possibilidade de se mobilizar uma equipe para atender todas as necessidades dos consumidores sujeitos aos seus serviços. O acórdão, como argumentação, expõe que, de fato, há previsão específica da Lei 8.987/95 e do CDC que demonstrem situações singulares que sujeitem a interrupção do serviço, mas, pela redação do art. 10 da Lei de Greve, é apontado que o serviço de fornecimento de energia é classificado em ordem essencial, e sua interrupção não abarcaria justificativas tais como as alegadas

8 Com suas devidas previsões dos art. 247 ao 249 do CC.

9 Detalhadamente, assim se expõe: Art. 4º: A Política Nacional das Relações de Consumo tem por objetivo o atendimento das necessidades dos consumidores, o respeito à sua dignidade, saúde e segurança, a proteção de seus interesses econômicos, a melhoria da sua qualidade de vida, bem como a transparência e harmonia das relações de consumo, atendidos os seguintes princípios: I - reconhecimento da vulnerabilidade do consumidor no mercado de consumo.

10 CANEZIN, Claudete Carvalho. Obrigações de fazer e de não fazer. relevância e aplicação nas relações de consumo. Revista Jurídica Cesumar. [S.I.] Vol. 1, nº 1, pág. 264, 2001.

11 Registra-se, desde já, a previsão das situações em que os agravos de instrumento são cabíveis (art. 1015, CPC).

12 CEARÁ, Tribunal de Justiça do Ceará (2ª Câmara Direito Privado do Tribunal de Justiça do Estado do Ceará). Agravo de Instrumento n⿳o 0623483-70.2020.8.06.0000. Ação de obrigação de fazer c/c reparação por dano moral e material. Fornecimento interrompido. Decisão a quo que deferiu o restabelecimento do fornecimento de energia e reparação às instalações elétricas. Serviço essencial. Covid-19. Previsão no decreto no 33.519, de 19 de março de 2020, ressalva por prestarem serviços essenciais. Ausência de elementos que evidenciam a probabilidade do direito e perigo de dano à recorrente. Agravante: Companhia Energética do Ceará - ENEL. Agravado: Laura Maria Garcia Bitu Pinto. Relator: Francisco Darival Beserra Primo, 17 de junho de 2020. Disponível em: https://tj-ce.jusbrasil.com.br/jurisprudencia/863889395/agravode-instrumento-ai-6234837020208060000-ce-0623483-7020208060000/inteiro-teor-863889405? ref=serp. Acesso em: $16 / 04 / 2021$. 
justamente por implicar em um prejuízo enorme à coletividade, ponto em que deixou de reconhecer o agravo de instrumento proferido pela empresa de energia, atendendo, portanto, ao direito do consumidor e mantendo a decisão do juízo a quo. A seguir, estão detalhados os trechos principais do acórdão que descrevem o caso:

(...) 2. A controvérsia recai sobre a alegação da concessionária de que não há equipe especializada para atendimento da determinação, e que, em decorrência do caos global que se instaurou por força do novo coronavírus (Covid-19), resta evidente a impossibilidade de cumprimento da determinação constante na tutela de urgência deferida, tendo em vista a situação em que o país encontra-se, estando de portas fechadas todo e qualquer ramo do comércio. (...)

4. Dessa forma, tanto a Lei 8.987/95, quanto o Código de Defesa do Consumidor, assenta a obrigação de prestação contínua dos serviços públicos, sendo a sua interrupção permitida apenas em hipóteses singulares, expressamente previstas no ordenamento jurídico. Ademais, vale consignar que a provisão de energia elétrica está inserida no rol de serviços essenciais previstos na Lei de Greve, constatemos: Art. 10 São considerados serviços ou atividades essenciais: I- tratamento e abastecimento de água; produção e distribuição de energia elétrica, gás e combustíveis;

5. Neste momento processual, diante de toda a conjuntura fática e jurídica apresentada, analisando o Decreto $\mathrm{n}^{\mathrm{o}}$ 33.519, de 19 de março de 2020, proferido pelo Governo do Estado do Ceará, que suspendeu o exercício de várias atividades econômicas e comerciais, ressalvou expressamente os distribuidores de energia elétrica, que podem funcionar por prestarem serviços essenciais. (...)

7. Recurso conhecido e desprovido. Decisão do juízo a quo mantida.

Ora, se tal acórdão demonstrou fundamentar-se devidamente às necessidades do caso concreto e, certamente, conferir a decisão necessária ao consumidor, a seguir se analisará um acórdão da mesma câmara de Direito Privado do caso anterior, onde um consumidor busca, por meio de apelação cível, revisão de contrato de financiamento de veículo com emissão de cédula de crédito bancário (CCB), onde os juros remuneratórios anteriormente acordados, ainda que anteriormente pactuados, representariam, para o mesmo, um valor acima do mercado para as condições econômicas em plena pandemia do coronavírus, ponto esse em que se sustenta seu pleitear em juízo. Divergindo do acórdão anterior, neste caso, o pedido do autor não foi atendido.

Obviamente, trata-se de um situação concreta diferente, vez em que permite diferentes interpretações pelo julgador. Todavia, ainda que a referida operação não abarque um serviço de natureza essencial, por exemplo, entende-se ser possível, minimamente, uma readequação dos valores pactuados em contrato, pois os próprios precedentes judiciais utilizados de base à fundamentação do julgador não implicaram em uma realidade tão ímpar como a do coronavírus. Assim, analisa-se em detalhes:

1. O recorrente pleiteia o reconhecimento da ilegalidade das taxas pactuadas no contrato, alegando terem sido fixadas acima dos valores médios de mercado, requerendo sua redução aos patamares médios à época da contratação.

2. A limitação da taxa de juros remuneratórios à média de mercado restringe-se às hipóteses em que seja verificada a abusividade do percentual e que represente uma vantagem exagerada à instituição financeira, a qual deve ficar cabalmente demonstrada em cada situação (Precedentes: REsp 407.097, RS; REsp 1.061.530, RS; AgRg no REsp 1.032.626, MS; AgRg no REsp 809.293, RS; AgRg no REsp 817.431, RS).

3. No caso em apreço, analisando o instrumento contratual às fls. 16-17, denota-se que foi estipulada a taxa de juros de 29,23\% ao ano. Realizada pesquisa no site do Banco do Central do Brasil, contata-se que a taxa média anual informada para o mesmo período e operação contratada (código de série 20.749) é de 22,17\% ao ano.

4. Verifica-se que a taxa de juros contratada é superior à taxa média de juros praticada pelo mercado, no entanto, não superando uma vez e meia a taxa de mercado, inexiste motivo que justifique a intervenção do Poder Judiciário. 
Portanto, quanto aos juros remuneratórios, não prosperam as razões do apelante, desmerecendo reforma a sentença de origem.

5. Recurso conhecido e improvido ${ }^{13}$.

Importante ressaltar a existência de muitos out ros casos de natureza semelhante aos apresentados em outras jurisdições, como no AI 0001830-45.2020.8.03.0000 (Amapá), AI 8014455-18.2020.8.05.0000 ${ }^{15}$ (Bahia), AI 0717652-22.2020.8.07.000016 (Distrito Federal), AI 14091570720208120000"17 (Mato Grosso do Sul), dentre vários outros. Ainda que não possam ser generalizados os efeitos elencados a todas as jurisdições nacionais, fica claro ser um problema com algum grau de vastidão em um bom número de tribunais.

Assim, analisando ambos os casos detalhados no presente item, fica bastante claro que a apreciação de situações que envolvam diretamente os males reflexos da pandemia, infelizmente, não gozam de certa uniformidade de decisões. Obviamente, muitos outros casos, antes mesmo da chegada da COVID-19, também não gozavam dessa referida uniformidade, mas parece claro que, sabendo que o consumidor possui, fundamentalmente, tal proteção legal nas relações de consumo, ao envolve-lo em situações extremas pelas quais o capitalismo se faz imperioso (afinal, assim se constrói a lógica de consumo e mercado), parece de maior prudência que os tribunais olhem para situações como a anterior e busquem uma maior harmonia, uma maior consonância com as dificuldades da parte consumidora.

13 CEARÁ, Tribunal de Justiça do Ceará (2ª Câmara Direito Privado do Tribunal de Justiça do Estado do Ceará). Apelação Cível no 0227592-92.2020.8.06.0001. Revisão de contrato de financiamento de veículo com emissão de cédula de crédito bancário. Juros remuneratórios - limitação à taxa média de mercado - impossibilidade no caso concreto. Valores pactuados dentro das taxas de mercado. Recurso conhecido e improvido. Apelante: Luis Roberto Alves de Sousa. Apelado: Itaú Unibanco S/A. Relatora: Maria de Fátima de Melo Loureiro, 07 de outubro de 2020. Disponível em: https://tj-ce. jusbrasil.com.br/jurisprudencia/941959085/apelacao-civel-ac-2275929220208060001-ce-0227592-9220208060001/ inteiro-teor-941959110/amp. Último acesso em: 16/04/2021.

14 AMAPÁ, Tribunal de Justiça do Amapá (Câmara Única do Egrégio Tribunal de Justiça do Estado do Amapá). Agravo de Instrumento n⿳o 0001830-45.2020.8.03.0000. Pandemia coronavírus. Redução da mensalidade. Possibilidade. Recurso não provido. Agravante: Associação Amapaense de Ensino e Cultura. Agravados: George Lucas Macêdo Vale e George Robert Vale dos Santos. Relator: Carlos Tork, 17 de setembro de 2020. Disponível em: https://tj-ap.jusbrasil.com. $\mathrm{br}$ /jurisprudencia/1102436907/agravo-de-instrumento-ai-18304520208030000-ap/inteiro-teor-1102436916. Acesso em: $17 / 08 / 2021$.

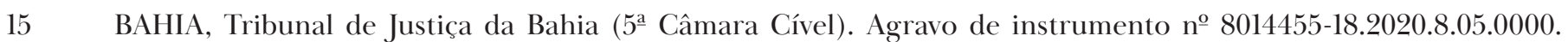
Ação de obrigação de não fazer. Deferimento parcial da tutela de urgência para determinar que a coelba se abstenha de interromper ou reestabeleça o fornecimento de energia elétrica a shopping center. Notoriedade dos efeitos da pandemia em relação aos shopping centers em geral. Impossibilidade de suspensão do serviço público essencial. Aplicação da resolução normativa № 878 / 2020 da ANEEL. Possibilidade de perseguir o direito de crédito. Multa diária adequada. Recurso conhecido e improvido. Decisão mantida. Agravante: Companhia de Eletricidade do Estado da Bahia Coelba. Agravado: Associação do Jua Garden Shopping. Relator: Baltazar Miranda Saraiva, 18 de agosto de 2020. Disponível em: https://tj-ba.jusbrasil.com. $\mathrm{br}$ /jurisprudencia/1121342918/agravo-de-instrumento-ai-80144551820208050000. Acesso em: 17/08/2021.

16 DiSTRITO FEDERAL, Tribunal de Justiça do Distrito Federal ( $1^{\underline{a}}$ Turma Cível). Agravo de instrumento $n^{o}$. 14091570720208120000. Direito civil. Direito do consumidor. Direito processual civil. Ação de rescisão contratual. Prestação de serviços turísticos. Cancelamento. Pandemia covid-19. Medidas de restrição de trânsito de pessoas e de convívio social. Resilição unilateral do negócio jurídico. Denúncia contrato. excepcionalidade. Medida provisória n. 925 /2020 convertida na lei 14.034/2020. Medida provisória n. 948/2020. Medidas emergenciais. Aviação civil. Setor turístico. Cancelamento de serviços ainda não prestados. Manutenção dos contratos celebrados. Remarcação dos serviços. Disponibilização do crédito. Mitigação do prejuízo. Reembolso. Suspensão da cobrança. Não cabimento. Recurso conhecido e não provido. Decisão mantida. Agravante: Julia Modesto Pinheiro Dias Pereira. Agravados: Girotrip Turismo Eireli e Banco do Brasil AS. Relator: Romulo de Araújo Mendes, 23 de setembro de 2020. Disponível em: https:/ / tj-df.jusbrasil.com.br/jurisprudenc ia/940988754/7176522220208070000-df-0717652-2220208070000. Acesso em: 17/08/2021.

17 MATO GROSSO DO SUL, Tribunal de justiça do Mato Grosso do Sul. Agravo de instrumento no 14091570720208120000. Tutela de urgência de caráter antecedente. Contrato de uso de sistema de distribuição. Shopping Center. Redução substancial de suas atividades em decorrência da pandemia de covid-19. Fato imprevisível e extraordinário. Aplicação da teoria da imprevisão. Preenchidos os pressupostos autorizadores para a concessão da tutela. Recurso provido. Agravante: Shopping Três Lagoas S.A. Agravado: Elektro Redes S.A. Relator: Divoncir Schreiner Maran, 19 de agosto de 2020. Disponível em: https://www.jusbrasil.com.br/processos/295926558/processo-n-1409157-0720208120000-do-tjms. Acesso em: $18 / 08 / 2021$. 


\section{Motivo de Força Maior e o Estado de Calamidade Pública como Motivadores à Reorganização dos Prazos Processuais e do Processo}

Se as questões anteriores já se mostravam suficientemente relevantes para o prejuízo nas apreciações processuais e seus andamentos (à exemplo da fase de saneamento), ultrapassando as questões de análise do mérito, passará a se aferir a ascensão do motivo de força maior nas questões da pandemia e como este atua como elemento ensejador da suspensão de prazos e processos.

Se a uniformidade quanto à apreciação dos tribunais no caso concreto não se construiu da forma que deveria, do ponto de vista do estabelecimento e reorganização dos prazos processuais, tal direcionamento pareceu mais consolidado. Nesse sentido, na data de 19 de março de 2020, fora emitida a Resolução no 313 do Conselho Nacional de Justiça que, além de ter estabelecido o regime de Plantão Extraordinário como forma de ampliar o tempo de atendimento às novas demandas (com exceção do Supremo Tribunal Federal e da Justiça Eleitoral (art. 1ํㅡ, caput, e parágrafo único)) e adotar a ferramenta de teletrabalho, suspendeu o curso dos prazos processuais a contar da data da publicação da própria resolução (19 de março), até o dia 30 de abril de 2020 (art. 5º ). A isso, não só houve uma aceleração na regulamentação do trabalho telepresencial no poder judiciário (que, em 2019, antes mesmo da pandemia, o CNJ já demonstrava avanços por meio da Resolução nº 298, de 22/10/2019) como também permitiu que o poder judiciário tivesse condições de delimitar e avançar às atividades essenciais a serem prestadas e, a partir disso, garantir condições de se reorganizar ao longo do ano de 2020 quanto à prática forense, uma vez que a pandemia avançaria para além de seu ano de início ${ }^{18}$.

E no que diz respeito aos tribunais superiores, também houve posicionamento pormenorizado: tratando do caso do STF, o mesmo editou a Resolução no 670 , de 23.03.2020, que suspendeu os prazos processuais de processos físicos temporariamente. Mas, ressalta-se, em conformidade com a já referida Resolução no 313 do Conselho Nacional de Justiça, são permitidas exceções quando da existência de situação urgente, especificamente por meio de seu art. $3^{\mathbf{0}}$, estabelecendo que o "atendimento judicial de partes, advogados, procuradores, defensores e interessados se dará por meio telefônico ou eletrônico, mantido o atendimento presencial ao público, inclusive o protocolo físico de petições, no horário de $13 \mathrm{~h}$ às $17 \mathrm{~h}$, exclusivamente para processos físicos urgentes" ${ }^{19}$.

Bem, a reorganização dos prazos e a suspensão do atendimento presencial parecem ser questões bastante óbvias a serem tomadas em um período emergencial (bem como uma maior tendência à aderência aos processos por via eletrônica, já em ascendência desde antes da pandemia ${ }^{20}$ ), mas o que de fato tais decisões mais positivamente impactam são em relação à garantia do acesso à justiça pelas partes.

Mais do que simplesmente suspender os prazos processuais, coube a própria suspensão do processo em seu momento, ponto em que se justifica: Quando se analisa a motivação de se declarar tal suspensão, seu fundamento está no art. 313, VI, do CPC ${ }^{21}$, não representando qualquer tipo de inovação,

18 DIAS, Victor Massante. A covid-19 e seus impactos no processo civil: uma análise sobre o motivo de força maior como ensejador da suspensão do processo e dos prazos, bem como de efeitos obstativos à preclusão. Revista de Processo, vol. $308 / 2020,2020$, p. 355 .

19 GAIO JÚNIOR, Antônio Pereira. Jurisdição civil brasileira em crise: desafios em tempos de pandemia. Revista Eletrônica de Direito Processual - REDP Rio de Janeiro. Ano 15. Volume 22. Número 1. Janeiro a Abril de 2021 , p. 90.

20 Como bem ressalta Antônio Pereira Gaio Júnior no artigo "Jurisdição civil brasileira em crise: desafios em tempos de pandemia", "Se estamos a falar do futuro da solução de disputas e dos limites que os efeitos pós-pandemia podem alcançar, notadamente, os contatos físicos em menor potencial já se colocam como algo palpável, sobretudo quando o consumo eletrônico por meio de compras na rede mundial de computadores bate recordes nestes tempos de isolamento social, tendo o e-commerce crescido $81 \%$ nestes tempos, sendo impulsionado por alimentos e bebidas". GAIO JÚNIOR, Antônio Pereira. Jurisdição civil brasileira em crise: desafios em tempos de pandemia. Revista Eletrônica de Direito Processual - REDP Rio de Janeiro. Ano 15. Volume 22. Número 1. Janeiro a Abril de 2021, p. 96. Dados extraídos em: https://www.ft.com/ content/19d90308-6858-11ea-a3c9-1fe6fedcca75.

21 Art. 313. Suspende-se o processo: [...] VI - por motivo de força maior. 
uma vez tal previsão já ter sido contemplada no CPC/73, por meio de seu art. 265, V22. Então, qual seu impacto central na situação abordada? Diferentemente da mera suspensão dos prazos, a suspensão do processo "não impede somente a prática de atos destinados ao cumprimento de um dever pelas partes, mas também aos impróprios, como aqueles que são praticados pelo juiz, que é sujeito desinteressado na relação jurídica processual" ${ }^{2324}$.

Por isso, tal paralização permite que todas as partes envoltas consigam se readequar às novas necessidades do período e tenham o devido acesso à justiça de forma justa e acessível, pois, afinal de contas, ainda que, como exposto, possa haver prejuízo no julgamento (em especial desde a fase de saneamento), tal condicionamento possibilitará uma maior segurança às partes, fazendo com que eventuais vícios, caso não sejam suprimidos ou corrigidos mediante apontamento do juiz competente, tenham o tempo correto para apreciar as questões centrais de análise, sejam elas de mérito ou procedimentais.

\section{Interferência na Autonomia Privada na Esfera do Processo Civil}

Diante das hipóteses até agora exploradas, um dos pontos mais sensíveis a se tratar corresponde ao prejuízo da autonomia privada. Aqui, não existe apenas uma óptica isolada de se tratar o tema, mas sim uma conjunção de perspectivas que, juntas, ajudaram a compor a presente tese.

Por autonomia privada, o sentido que se pretende atingir é o de busca dos interesses privados em determinada relação jurídica. Ora, quando se está tratando do próprio processo civil, parece óbvio que este é um princípio fundante, visto que as partes provocam o poder judiciário para conseguirem atingir o interesse pessoal frente à parte contrária. A questão que se levanta nesse capítulo, no entanto, é que tal lógica acaba por ser relativizada em uma realidade de pandemia, tanto para o bem como para o mal. Para o bem porque, diante de situações adversas, não parece certo que a apreciação do julgador seja a mesma de antes da COVID-19, que trouxe novas variáveis. E para mal - e aqui se estabelece o foco do capítulo - porque nem sempre tais apreciações serão as mais corretas em relação ao caso concreto, que passa a ter ainda mais importância, dada a dificuldade de subsunção com todos os novos desafios que surgiram.

Nesse sentido, Souza e Silva apontam que, em situações de crise que requeiram intervenção do judiciário, a doutrina naturalmente passa a "propor possíveis qualificações jurídicas para a crise, de modo a atrair a incidência da normativa que parece ser mais adequada a administrá-la" ${ }^{25}$. Mas, ainda que haja tal empenho, a pluralidade de novas demandas e a multiplicidade de perspectivas dos julgadores podem refletir em problemas no caso concreto, conforme apontam novamente os autores supracitados:

O empenho subjacente à pluralidade de proposições pode, contudo, ser prejudicial (em vez de benéfico), caso não seja acompanhado do devido respeito aos fundamentos e requisitos próprios de cada instituto. Sem dúvida, o novo coronavírus representa uma novidade fática, porém não inovou na ordem jurídica: as categorias normativas continuam sendo as mesmas de sempre - e, ao menos no campo estrito do direito privado, não parece conveniente

\section{Idem.}

23 Idem.

24 Importante também salientar o posicionamento de Luis Guilherme Aidar Bondio em sua obra "Comentários ao CPC" onde, ao comparar os casos do art. 313 com o art. 1004, clarifica que enquanto o segundo (referente à morte da parte ou de advogado) implica no reinício da contagem de prazo, as situações previstas no primeiro, por outro lado, demonstram que os prazos se interrompem, sendo contados a partir do reestabelecimento da contagem dos prazos (sendo esse o ponto incidido na pesquisa) : "Em outras palavras, enquanto o art. 1.004 do CPC trata a morte da parte ou de seu advogado e o evento de força maior como causas de interrupção do prazo para recorrer já deflagrado, que se reinicia por completo ("começa a correr novamente") após a superação do fato interruptivo, o art. 221 do CPC, lido conjuntamente com os incisos I e VI do art. 313 do CPC, disciplina esses mesmos acontecimentos como causas de suspensão dos prazos, devolvendo para a parte apenas o tempo faltante para o esgotamento destes". BONDIOL, Luis Guilherme A. Comentários ao CPC, v. XX, $2^{a}$ edição. Editora Saraiva, 2017, p. 69.

25 SOUZA, Eduardo Nunes de; SILVA, Rodrigo da Guia. Resolução contratual nos tempos do novo coronavírus. Migalhas. [S. 1.], 25 mar. 2020. Disponível em: https://www.migalhas.com.br/coluna/migalhas-contratuais/322574/ resolucao-contratual-nostempos-do-novo-coronavirus. Acesso em: 10 de março de 2021. 
a edição de leis de afogadilho, fomentadas pela incerteza e pela ansiedade generalizadas causadas pela pandemia. Cabe ao intérprete, assim, à semelhança do criterioso trabalho desempenhado pelos cientistas de outras áreas, manejar os instrumentos jurídicos com técnica e segurança, sempre com vistas a promover estabilidade (e não a agravar as incertezas ínsitas ao momento ${ }^{26}$.

Um exemplo de caso concreto que certamente deixa clara a ameaça de tal estabilidade é o de relações de consumo em planos de saúde ${ }^{27}$. Bem, trata-se de fato notório e, especialmente, delicado, pois ainda que, como referido, envolva uma relação de consumo (empresa que oferece o plano e o consumidor), facilmente se ultrapassa tal esfera, diretamente vinculada ao direito à saúde e sua proteção constitucional.

Em uma situação de pandemia, os panos de saúde obviamente foram muito mais acionados do que em outras épocas, uma vez a demanda de questões da COVID-19 ter surgido e se somado às outras já existentes. E, além disso, como o elevado número de pessoas tendo de ser submetidas a uma UTI atingiu números altíssimos, o pagamento dessas diárias igualmente aumentou a onerosidade para cobrimento das empresas de plano de saúde, gerando prejuízos enormes às mesmas. Por isso, parece claro que, internamente, precisou-se adotar uma filtragem maior em relação a quais situações de saúde o plano seria capaz de cobrir, o que tende a gerar questionamentos e judicialização dos contratantes.

Nesse sentido, os trechos do seguinte acórdão detalham uma situação em que uma cliente precisou passar por intervenções cirúrgicas com certa complexidade diante de evidente patologia (segundo a redação do próprio acórdão: "realização de mamoplastia redutora como tratamento para "dorsalgia crônica de caráter mecânico"”). A empresa do plano de saúde, no entanto, tentou questionar a cobertura proposta e, mediante agravo de instrumento, tentou reverter o reconhecimento de anterior decisão interlocutória, alegando que o procedimento seria de natureza estética.

A seguir, são analisados os trechos:

1. Cuida-se de agravo de instrumento movido em face de decisão interlocutória que determinou ao plano de saúde agravante o custeio de cirurgia redutora mamária, conforme solicitado pela parte agravada;

2. Cinge-se a demanda acerca da legalidade da negativa de cobertura do plano de saúde para o procedimento cirúrgico prescrito por médico assistente da recorrida, que determinou a realização de mamoplastia redutora como tratamento para "dorsalgia crônica de caráter mecânico", sob o argumento de tratar-se de procedimento estético não coberto pelo plano;

3. Cabe ao médico e não ao plano de saúde determinar qual o tratamento adequado para a obtenção da cura. Precedentes.

4. Comprovado nos autos que a cirurgia de redução mamária foi devidamente prescrita por médico assistente para correção de patologia que acometia a apelada, causando-lhe dores e desconforto na coluna vertebral, não pode ser negada a cobertura sob o enfoque de procedimento meramente estético não albergado pelo plano de saúde.

5. Agravo de Instrumento conhecido e improvido ${ }^{28}$.

26 SOUZA, Eduardo Nunes de; SILVA, Rodrigo da Guia. Resolução contratual nos tempos do novo coronavírus. Migalhas. [S. 1.], 25 mar. 2020. Disponível em: https://www.migalhas.com.br/coluna/migalhas-contratuais/322574/ resolucao-contratual-nostempos-do-novo-coronavirus. Acesso em: 10 de março de 2021.

27 Tal como exposto pela Súmula 608 do STJ - Aplica-se o Código de Defesa do Consumidor aos contratos de plano de saúde, salvo os administrados por entidades de autogestão.

28 CEARÁ, Tribunal de Justiça do Ceará (4⿳⺈⿴囗十一 Câmara Direito Privado do Tribunal de Justiça do Estado do Ceará). Agravo de Instrumento n⿳o: 0626490-70.2020.8.06.0000. Direito do consumidor. Agravo de instrumento. Plano de saúde. Paciente acometida de hipertrofia mamária. Prescrição médica de mamoplastia redutora. Negativa de cobertura. Caráter estético do tratamento. Recusa indevida. Fins meramente estéticos não configurados. Recurso conhecido e improvido. Agravante: Unimed Fortaleza - Sociedade Cooperativa Médica Ltda. Agravado: Maria Amanda Oliveira Sampaio. Relator: Durval Aires Filho, 29 de setembro de 2020. Disponível em: https://tj-ce.jusbrasil.com.br/jurisprudencia/935432180/agravo-deinstrumento-ai-6264907020208060000-ce-0626490-7020208060000/inteiro-teor-935432194. Acesso em: 16/04/2021. 
Felizmente, a apreciação feita pelos julgadores conseguiu atender à real necessidade da parte agravada, que de fato possuía uma patologia e, consequentemente, deveria ter seu tratamento coberto pelo plano de saúde. Mas, ao se analisar os argumentos da empresa do plano de saúde, fica bastante claro o perigo representado ao direito da paciente caso os julgadores não tivessem apreciado o caso concreto corretamente ("Cabe ao médico e não ao plano de saúde determinar qual o tratamento adequado para a obtenção da cura”). E, ainda que possivelmente houvesse dúvidas se o plano cobriria ou não tal operação (como na existência de alguma cláusula limitadora de preço de tratamento), o direito à saúde deve se sobrepor a autonomia privada e negocial exposta pelas partes, assim sendo imperiosa a $\mathrm{CF}^{29}$.

\section{Conclusão Final e Comentário do Professor Calmon de Passos}

Diante de todas as dificuldades advindas da pandemia da COVID-19, tanto para a atividade processual quanto para as questões contratuais-consumeristas submetidas, cabe uma breve e pertinente colocação do professor Calmon de Passos: "pouco importam os mandamentos dos deuses para os que não tem fé, bem como de nada valem as proclamações de direitos para os que não têm consciência do dever" ${ }^{\prime \prime}$.

Apesar de o notório professor não ter vivenciado um período emergencial como o presente, sua declaração apresenta-se em clara consonância com a situação-objeto do artigo, pois depreende-se que os desafios de se enfrentar as absolutas excepcionalidades contemporâneas da pandemia pressupõem de forças conjuntas que sejam conscientes de suas responsabilidades e, mais além, de suas funções perante à coletividade. Por vias de análise da obra "Direito, Poder, Justiça e Processo: Julgando os que nos Julgam”, fica clara a pluralidade de forças que devem ser empregadas na manutenção do poder comum, seja no âmbito político (executivo e legislativo), seja no próprio âmbito jurídico. E aqui, diante de todo o exposto dessa pesquisa, entendendo ser a atividade processual um meio pelo qual se propõe a resolução de uma lide, de um conflito entre as partes, óbvio parece que, quanto mais caótica se encontra a situação social, mais dificultoso é o emprego do aparato judicial para resolver tais problemas.

Por isso, ao longo do artigo, procurou ser exposta a mobilização de tribunais de diferentes estados e diferentes instâncias (tanto tribunais de primeira instância quanto tribunais superiores, como o STF e o STJ), pois diante de todas as adversidades decorrentes da pandemia em si, caso a conscientização decorresse apenas de forma isolada em alguns órgãos e agentes do judiciário, de nada adiantaria, pois não seriam passados os reais benefícios à coletividade que, constitucionalmente, devem ser o norte da atuação do agente público. Ainda que alguns impactos só possam ser mensurados em um recorte regional, resta claro a pluralidade de efeitos no período.

\section{Referências}

AMAPÁ, Tribunal de Justiça do Amapá (Câmara Única do Egrégio Tribunal de Justiça do Estado do Amapá). Agravo de Instrumento nº 0001830-45.2020.8.03.0000. Pandemia coronavírus. Redução da mensalidade. Possibilidade. Recurso não provido. Agravante: Associação Amapaense de Ensino e Cultura. Agravados: George Lucas Macêdo Vale e George Robert Vale dos Santos. Relator: Carlos Tork, 17 de setembro de 2020. Disponível em: https://tj-ap.jusbrasil. com.br/jurisprudencia/1102436907/agravo-de-instrumento-ai-18304520208030000-ap/inteiroteor-1102436916. Acesso em: 17/08/2021;

BACCARIN, Cínthia. CORDIOLI, Hiago Andrioti. CANAVEZ, Luciana Lopes. Revista de Direitos Fundamentais nas Relações do Trabalho, Sociais e Empresariais. v. 6, n. 2, p. 01 - 21, Jul/Dez. 2020

29 Com específica previsão dada nos art. 196 a 200, CF.

30 PASSOS, J. J. Calmon de. Direito, Poder, Justiça e Processo: Julgando os que nos Julgam, cit., p. 101. In: SOUZA, Marcus Seixas. Pandemia, Direito e Solidariedade: O Que Diria Calmon? Revista ANNEP de Direito Processual, Vol. 1, No. 2, Art. 30, 2020. Disponível em: https://doi.org/10.34280/annep/2020.vli2.30. 
BAHIA, Tribunal de Justiça da Bahia (5 $5^{\text {a }}$ Câmara Cível). Agravo de instrumento no $8014455^{-}$ 18.2020.8.05.0000. Ação de obrigação de não fazer. Deferimento parcial da tutela de urgência para determinar que a coelba se abstenha de interromper ou reestabeleça o fornecimento de energia elétrica a shopping center. Notoriedade dos efeitos da pandemia em relação aos shopping centers em geral. Impossibilidade de suspensão do serviço público essencial. Aplicação da resolução normativa № 878/2020 da ANEEL. Possibilidade de perseguir o direito de crédito. Multa diária adequada. Recurso conhecido e improvido. Decisão mantida. Agravante: Companhia de Eletricidade do Estado da Bahia Coelba. Agravado: Associação do Jua Garden Shopping. Relator: Baltazar Miranda Saraiva, 18 de agosto de 2020. Disponível em: https://tj-ba.jusbrasil.com.br/jurisprudencia/1121342918/agravo-de-instrumentoai-80144551820208050000. Acesso em: 17/08/2021;

BONDIOL, Luis Guilherme A. Comentários ao CPC, v. XX, 2ª edição: Editora Saraiva, 2017;

CANEZIN, Claudete Carvalho. Obrigações de fazer e de não fazer. relevância e aplicação nas relações de consumo. Revista Jurídica Cesumar. [S.I.] Vol. 1, nº 1, pág. 261-277, 2001;

CEARÁ, Tribunal de Justiça do Ceará (2 ${ }^{a}$ Câmara Direito Privado do Tribunal de Justiça do Estado do Ceará). Agravo de Instrumento no 0623483-70.2020.8.06.0000. Ação de obrigação de fazer c/c reparação por dano moral e material. Fornecimento interrompido. Decisão a quo que deferiu o restabelecimento do fornecimento de energia e reparação às instalações elétricas. Serviço essencial. Covid-19. Previsão no decreto no 33.519, de 19 de março de 2020, ressalva por prestarem serviços essenciais. Ausência de elementos que evidenciam a probabilidade do direito e perigo de dano à recorrente. Agravante: Companhia Energética do Ceará - ENEL. Agravado: Laura Maria Garcia Bitu Pinto. Relator: Francisco Darival Beserra Primo, 17 de junho de 2020. Disponível em: https://tj-ce.jusbrasil.com.br/jurisprudencia/863889395/ agravo-de-instrumento-ai-6234837020208060000-ce-0623483-7020208060000/inteiro-teor863889405? ref=serp. Último acesso em: 16/04/2021;

CEARÁ, Tribunal de Justiça do Ceará (4-a Câmara Direito Privado do Tribunal de Justiça do Estado do Ceará). Agravo de Instrumento nº: 0626490-70.2020.8.06.0000. Direito do consumidor. Agravo de instrumento. Plano de saúde. Paciente acometida de hipertrofia mamária. Prescrição médica de mamoplastia redutora. Negativa de cobertura. Caráter estético do tratamento. Recusa indevida. Fins meramente estéticos não configurados. Recurso conhecido e improvido. Agravante: Unimed Fortaleza - Sociedade Cooperativa Médica Ltda. Agravado: Maria Amanda Oliveira Sampaio. Relator: Durval Aires Filho, 29 de setembro de 2020. Disponível em: https://tj-ce.jusbrasil.com.br/jurisprudencia/935432180/agravo-de-instrumento-ai6264907020208060000-ce-0626490-7020208060000/inteiro-teor-935432194. Último acesso em: $16 / 04 / 2021$;

CEARÁ, Tribunal de Justiça do Ceará (2a Câmara Direito Privado do Tribunal de Justiça do Estado do Ceará). Apelação Cível no 0227592-92.2020.8.06.0001. Revisão de contrato de financiamento de veículo com emissão de cédula de crédito bancário. Juros remuneratórios - limitação à taxa média de mercado - impossibilidade no caso concreto. Valores pactuados dentro das taxas de mercado. Recurso conhecido e improvido. Apelante: Luis Roberto Alves de Sousa. Apelado: Itaú Unibanco S/A. Relatora: Maria de Fátima de Melo Loureiro, 07 de outubro de 2020. Disponível em: https://tj-ce.jusbrasil.com.br/jurisprudencia/941959085/apelacao-civelac-2275929220208060001-ce-0227592-9220208060001/inteiro-teor-941959110/amp. Acesso em: $16 / 04 / 2021$;

CONSELHO Nacional de Justiça. Justiça em Números 2021. Brasília, DF: 2021. Disponível em: https:// www.cnj.jus.br/wp-content/uploads/2021/09/relatorio-justica-em-numeros2021-12.pdf;

CONSELHO Nacional de Justiça. TST aumenta em 6,3\% a quantidade de processos julgados em 2020. Disponível em: https://www.cnj.jus.br/tst-aumenta-em-63-a-quantidade-de-processos-julgadosem-2020/. Último acesso em: 11/07/2021; 
DIAS, Victor Massante. A covid-19 e seus impactos no processo civil: uma análise sobre o motivo de força maior como ensejador da suspensão do processo e dos prazos, bem como de efeitos obstativos à preclusão. Revista de Processo, vol. 308/2020, p. 351 - 368, Out / 2020;

DISTRITO FEDERAL, Tribunal de Justiça do Distrito Federal (1 $1^{\underline{a}}$ Turma Cível). Agravo de instrumento no . 14091570720208120000. Direito civil. Direito do consumidor. Direito processual civil. Ação de rescisão contratual. Prestação de serviços turísticos. Cancelamento. Pandemia covid-19. Medidas de restrição de trânsito de pessoas e de convívio social. Resilição unilateral do negócio jurídico. Denúncia contrato. excepcionalidade. Medida provisória n. 925/2020 convertida na lei 14.034/2020. Medida provisória n. 948/2020. Medidas emergenciais. Aviação civil. Setor turístico. Cancelamento de serviços ainda não prestados. Manutenção dos contratos celebrados. Remarcação dos serviços. Disponibilização do crédito. Mitigação do prejuízo. Reembolso. Suspensão da cobrança. Não cabimento. Recurso conhecido e não provido. Decisão mantida. Agravante: Julia Modesto Pinheiro Dias Pereira. Agravados: Girotrip Turismo Eireli e Banco do Brasil AS. Relator: Romulo de Araújo Mendes, 23 de setembro de 2020. Disponível em: https://tj-df.jusbrasil.com.br/jurisprudencia/940988754/7176522220208070000df-0717652-2220208070000. Acesso em: 17/08/2021;

ENUNCIADOS do Fórum Permanente de Processualistas Civis. Florianópolis, 2017. Disponível em: https://institutodc.com.br/wp-content/uploads/2017/06/FPPC-Carta-de-Florianopolis.pdf. Acesso em: 22/04/2021;

ESCOLA Superior do Ministério Público da União. Especialista analisa desafios enfrentados pelo direito processual civil e as perspectivas após a pandemia. Brasília, DF: 2020. Disponível em: http://escola.mpu.mp.br/a-escola/comunicacao/noticias/especialista-analisa-desafiosenfrentados-pelo-direito-processual-civil-e-as-perspectivas-futuras-apos-a-pandemia

GAIO JÚNIOR, Antônio Pereira. Jurisdição civil brasileira em crise: desafios em tempos de pandemia. Revista Eletrônica de Direito Processual - REDP Rio de Janeiro. Ano 15. Volume 22. Número 1. Janeiro a Abril de 2021;

MATO GROSSO DO SUL, Tribunal de justiça do Mato Grosso do Sul. Agravo de instrumento no 14091570720208120000. Tutela de urgência de caráter antecedente. Contrato de uso de sistema de distribuição. Shopping Center. Redução substancial de suas atividades em decorrência da pandemia de covid-19. Fato imprevisível e extraordinário. Aplicação da teoria da imprevisão. Preenchidos os pressupostos autorizadores para a concessão da tutela. Recurso provido. Agravante: Shopping Três Lagoas S.A. Agravado: Elektro Redes S.A. Relator: Divoncir Schreiner Maran, 19 de agosto de 2020. Disponível em: https://www.jusbrasil.com.br/ processos/295926558/processo-n-1409157-0720208120000-do-tjms. Acesso em: 18/08/2021;

PASSOS, J. J. Calmon de. Direito, Poder, Justiça e Processo: Julgando os que nos Julgam. Rio de Janeiro: Forense, 2000;

SOUZA, André Pagani de. CARACIOLA, Andrea Boari. ASSIS, Carlos Augusto de. FERNANDES, Luís Eduardo Simardi. DELLORE, Luiz. Teoria Geral do Processo Contemporâneo, 4⿳亠丷a edição. Grupo GEN, 2018;

SOUZA, Marcus Seixas. Pandemia, Direito e Solidariedade: O Que Diria Calmon? Revista ANNEP de Direito Processual Vol. 1, No. 2, Art. 30, 2020. Disponível em: https://doi.org/10.34280/ annep/2020.vli2.30. Acesso em: 15/06/2021;

TRECENTI, Julio. NUNES, Marcelo Guedes. Impacto do Covid-19 no judiciário de São Paulo. Migalhas, 6 de abril de 2020. Disponível em: https://www.migalhas.com.br/depeso/323691/ impacto-do-covid-19-no-judiciario-de-sao-paulo. Acesso em: 08/03/2021. 